\title{
BASES PARA UN IUS COMMUNE PRIVADO LATINOAMERICANO: BREVE ANÁLISIS DE OBJEGIONES Y MATERIALES JURÍDICOS*
}

\section{THE LEGAL BASIS FOR A LATIN AMERICAN PRIVATE IUS COMMUNE: BRIEF ANALYSIS OF OBJECTIONS AND LEGAL MATERIALS}

John Alberto Tito AÑAMURO**

RESUMEN: El presente trabajo propone sentar unas bases para construir un ius commune privado latinoamericano, a cuyo efecto examina las secuencias jurídicas regulares desde el derecho indiano hasta el derecho positivo actual, y defiende que, previo a todo intento de armonización positiva, es relevante la creación de una cultura jurídica común latinoamericana. Un primer paso para ello es formular un programa de trabajo que unifique lo asistemático de las propuestas de uniformización jurídica actuales.

Palabras clave: Integración, economía, armonización, derecho, ius commune, contrato, América Latina.
ABSTRACT: This paper aims to lay a foundation to build a Latin American private ius commune, for which examines the regular sequences from Indian law to current positive law and defends that, prior to any attempt at positive harmonization, the creation of a common legal culture Latin American is more important, and a first step to this is a programme of work that unifies the unsystematic current legal harmonization proposals.

Keyzeords: Integration, economy, law, harmonization, ius commune, contract, Latin America.

* Artículo recibido el 28 de agosto de 2015 y aceptado para su publicación el 23 de enero de 2016.

** Doctor en derecho por la Universidad de Salamanca (España); investigador permanente del Max-Planck-Institut de Hamburgo (Alemania) y profesor de derecho privado patrimonial de la Universidad del Norte (Colombia). El presente trabajo es fruto del desarrollo del proyecto "Armonización del derecho comercial y de consumo desde los principios pro consumatore", que patrocina la DIDI de la Universidad del Norte, Colombia.

Boletín Mexicano de Derecho Comparado nueva serie, año XLIX, núm. 146, mayo-agosto de 2016, pp. 253-279.

D. R. C 2016. UNAM, Instituto de Investigaciones Jurídicas. 
Esta revista forma parte del acervo de la Biblioteca Jurídica Virtual del Instituto de Investigaciones Jurídicas de la UNAM

Sumario: I. Planteamiento. II. Racionalidad del proyecto. III. Contra la idea de unidad: resistencia y diversidad. IV. Bases para un ius commune privado latinoamericano: breve análisis. V. Conclusiones. VI. Bibliografia.

\section{Planteamiento}

Si tuviéramos entre manos un código común de derecho privado, sería un momento encerrado casi en la utopía del derecho latinoamericano. Además, si ese punto en el horizonte es aún inalcanzable en derecho europeo, que son los verdaderos artífices de la integración económica y armonización jurídica, hasta arrogante llegaría a ser su defensa.

Entonces, ¿cómo pretender la uniformización en Latinoamérica, si no se tiene un mercado único, condición básica de toda armonización de derecho?

Bajo este interrogante, todos los trabajos orientados a la unidad jurídica no serían más que la sombra de un objetivo inocuo y absurdo, si se parte de la idea de que se trata de un escenario embrionario en integración económica y asistemático en propuestas de unificación.

Así las cosas, un artículo como este, que busca recoger las bases de un derecho privado regional, rozaría, en las condiciones arriba mencionadas, con lo irrazonable y absurdo y, en consecuencia, no tendría sentido. Pero, como no todas las corrientes de construcción del pensamiento son diseños cerrados, consideramos que es posible presentar y examinar la alternativa de construir, desde abajo, una propuesta de gestación de un ius commune privado. La primera piedra sería la generación, impulso y consolidación de una cultura jurídica común de los pueblos latinoamericanos: un programa que anteponga el derecho a la ley escrita o, dicho de otro modo, el ius antes que la lex.

Tal alternativa soslayaría, no sólo las estructuras europeas de producción normativa, política legislativa y los planes de acción, sino además la condición de existencia de un mercado único latinoamericano. Esa salida, situada fuera de la esfera del derecho positivo, no es otra que la construcción académica de un programa de armonización generado desde las manos de juristas, la doctrina y la jurisprudencia, sin perder de vista la prospección de que en algún momento se dé la integración de un merca- 
Esta revista forma parte del acervo de la Biblioteca Jurídica Virtual del Instituto de Investigaciones Jurídicas de la UNAM

do regional único. Mientras ello llegue, la labor se reduce a promover una cultura jurídica común latinoamericana. ${ }^{1}$

En esta lógica, este texto examina un modelo de uniformización en sus necesidades, condiciones y objeciones, en busca de un escenario de diálogo, discusión y elaboración gradual de un tejido jurídico latinoamericano que como condición descanse primero en el derecho y luego en la ley positiva.

\section{RAGIONALIDAD DEL PROYECTO}

Lo primero que se ha de decir es que llevar a cabo una acción comunitaria de armonización de sistemas jurídicos nacionales es una tarea que descansa, no sólo en la racionalidad del proyecto, sino en soslayar estimaciones subjetivas o emotivas de la unificación económica y jurídica a lo largo de su evolución.

Si se toma en cuenta esto último, no se pueden cerrar los ojos a la historia racional del derecho latinoamericano. Frente a ello, cabe recordar que en época de la Colonia se neutralizó la creación jurídica ex novo de los pueblos indígenas y se impuso un orden normativo desde la Corona, que a efectos de formación del derecho fue el primer desplazamiento de normas extranjeras a territorio local o el primer legal transplant del nuevo mundo.

Después del derecho indiano, en época de las codificaciones, los países latinoamericanos copiaron el modelo del Código Civil francés, el cual fue, desde nuestra óptica, un segundo desplazamiento de normas desde los sitios de producción de derecho (SPD) a los sitios de recepción de derecho (SRD) o, lo que es igual, un segundo legal transplant de Europa al nuevo mundo. La consecuencia negativa de esto fue dejar en la sombra toda ingeniería de conocimiento jurídico auténtico; es decir, la del derecho indígena.

Ahora bien, si se ve detenidamente la realidad jurídica actual, las cosas no han cambiado mucho. Se siguen copiando estructuras de derecho $(\mathrm{ED})^{2}$ de SPD a SRD. La única variable es que ahora hay más de un mo-

1 Tito Añamuro, John, "Hacia un modelo de armonización del derecho contractual latinoamericano", 126, Vniversitas, 2013, p. 264.

2 En sentido pragmático, una estructura de derecho es una norma jurídica, un concepto jurídico, una institución jurídica, un principio jurídico, un enunciado o un brocardo jurídico, entre otros análogos. Estas estructuras están sujetas al cambio, por lo que algunas 
Esta revista forma parte del acervo de la Biblioteca Jurídica Virtual del Instituto de Investigaciones Jurídicas de la UNAM

delo para copiar. Si antes los modelos eran el Code francés de 1804 y el BGB alemán de 1900, hoy el modelo de copia es la producción jurídica de la Unión Europea, dentro de la cual destacan los trabajos de unificación del derecho privado europeo.

En suma, los materiales para copiar de SPD han aumentado, y la constante de usar el copy paste en SRD permanece casi inalterable. En este orden de ideas, la falta de una tradición de escuelas de pensamiento o de generación de conocimiento de nivel SPD encaja en la mayoría de supuestos como la causa de permanencia de esa constante latinoamericana del copy paste normativo. ${ }^{3}$ En tal circunstancia, no parece existir más alternativa que seguir copiando normativa extranjera.

Si América Latina no ha evolucionado a nivel de SPD, es porque hoy no es competitiva. Este primer ejercicio de retroacción, quizá más bien de honestidad, pone de manifiesto dos situaciones racionales: una, no se abandonará la copia entretanto no haya evidencia y resultados de la evolución auténtica del derecho latinoamericano; y dos, corresponden hoy la gestación, impulso y consolidación de escuelas de pensamiento jurídico en la región que inicien, desde la educación básica a la superior, la construcción gradual de una conciencia jurídica común latinoamericana. ${ }^{4}$

se mantienen estables y otras tienden a desaparecer o salen de los sistemas jurídicos. En este último caso, pierden efectos obligatorios. En el orden teórico, una estructura de derecho sería la "unidad jurídica fácticamente existente y sensible a fluctuaciones en el mundo del derecho; vigente, en términos menos rígidos, si se quiere, dado que por lo menos algún efecto jurídico despliega en la práctica, piénsese en una norma jurídica o en la del concepto de propiedad o en la regla constitucional o en uno más complejo como la fuerza vinculante del precedente judicial". Véase al respecto Tito Añamuro, John, Modernización e integración del derecho contractual latinoamericano, Barranquilla, Ediciones Uninorte, 2012, p. 15.

3 Véase al respecto, Tito Añamuro, John, Modernización e integración del derecho contractual..., cit., pp. 67 y ss. En este orden, aunque los tiempos han cambiado, merced a la sociedad de la información y revolución digital, América Latina aún no es competitiva para imponer un modelo de derecho ni menos una ED hacia los SPD europeos. Aunque no obsta que un día lo sea, pues en la actualidad siguen existiendo, en los viejos resortes de la recepción del derecho, copias y malas copias de los SPD en los distintos sistemas jurídicos latinoamericanos.

4 Una muestra de ello es la propuesta de Juan Pablo Pampillo, quien destaca que "la integración jurídica del hemisferio americano es uno de los temas más relevantes para los juristas de nuestro continente y que la razón es que el derecho de la integración se nos presenta cada vez más como el nuevo paradigma jurídico del siglo XXI, así como durante la segunda mitad del siglo XX lo fueron los derechos humanos". Pampillo, Juan, "El derecho de la integración americana: una invitación a los juristas a conformar un nuevo 
Esta revista forma parte del acervo de la Biblioteca Jurídica Virtual del Instituto de Investigaciones Jurídicas de la UNAM

\section{CONTRA LA IDEA DE UNIDAD: RESISTENCIA Y DIVERSIDAD}

Unidad y diversidad son dos categorías difíciles de coordinar en el ámbito del conocimiento humano. Si se defiende la unidad, no resultará difícil concluir que la diversidad fue poco priorizada, pero como ambas son, en estricto sentido, dos lados de una moneda, no corresponde una defensa cerrada de ninguna de ellas, consideradas individualmente.

En la unificación del derecho privado, esta dualidad pone de manifiesto una de sus mayores dificultades: la conciliación de ambas categorías. La razón descansa en que a menudo resulta difícil hallar puntos de conexión entre los elementos que componen tal dualidad, como se verá en seguida.

\section{Disparidad normativa y freno a la velocidad del mercado}

En el ámbito del derecho, no se trata de reducir la diversidad a la unidad, porque eso es imposible. Lo que sí puede hacerse es defender la edificación de un modelo normativo que gradualmente busque la aproximación de las distintas pautas de derecho, sobre la base de rasgos jurídicos comunes, respetando los iura propria de los derechos locales. Dicho de otro modo, la orientación es hacia la construcción de un tejido jurídico común, que no vulnere el ámbito de lo local, en orden a que este puede seguir desarrollándose.

Para la construcción de este modus de unidad, la disparidad normativa es un obstáculo que debe ser superado, dado que frena la dinámica y velocidad del mercado; es decir, los movimientos transfronterizos de personas, servicios, capitales y solución de problemas conjuntos, con todas las consecuencias negativas que esto supone en el ámbito de la economía. ${ }^{5}$

Dicha disparidad no se presenta del mismo modo en un sistema jurídico u otro. Pero lo que sí se presenta, como factor constante, es la dualidad "unidad y pluralidad".

Con esto último, y el problema de freno a la dinámica del mercado, es posible deducir que entre los sistemas latinoamericano y europeo hay

ius commune", en Pampillo Baliño, Juan Pablo (coord.), Derecho supranacional, globalización e integración jurídica, México, Porrúa, 2012, p. 375.

5 En detalle sobre la dinámica del mercado europeo, González Martín, Nuria, "Unión Europea: bases de su marco jurídico", en Pampillo Baliño, Juan Pablo (coord.), Derecho supranacional, globalización e integración jurídica, México, Porrúa, 2012, pp. 273 y ss. 
Esta revista forma parte del acervo de la Biblioteca Jurídica Virtual del Instituto de Investigaciones Jurídicas de la UNAM

un modo distinto de afrontar la disparidad legislativa. En rigor, ese modo distinto, ese "cómo" [rectius: ese proceso] es lo que interesa saber.

\section{A. Neutralizar la diversidad}

El punto de convergencia entre los sistemas jurídicos europeo y latinoamericano, en nuestra opinión, es la acción constante de mitigar el impacto de la diversidad, mediante intentos de aproximación de derecho internacional privado, derecho comparado o la uniformización jurídica a la que aspira llegar la Unión Europea, por ejemplo. Si la diferencia está en el "cómo", parece entonces razonable una autoorganización.

Una muestra de recoger esa diversidad en un cuerpo de normas ha sido el viejo modelo de unificación de derecho internacional privado latinoamericano de 1928 o Código de Bustamante, de cuyos procesos y estrategias de diálogo y construcción se pueden extraer puntos de referencia y de análisis para la armonización del derecho sustantivo latinoamericano, que se propone, en la actualidad. Con lo cual, el dato relevante es que la labor de mitigar la dispersión en América Latina no es desconocida para los operadores jurídicos. ${ }^{6}$

\section{B. Legitimidad de la regulación local}

La producción normativa local en los distintos sistemas jurídicos no es un acto que roce con el absurdo ni se halla proscrita, sino todo lo contrario, ésta es legítima, dado que por definición es el punto de partida de toda arquitectura normativa de orden general. Si hiciéramos un breve repaso por la construcción de los diferentes sistemas normativos, caeríamos en la cuenta de que la pluralidad jurídica es fruto de las bases políticas, económicas, sociales y culturales de cada uno de los ordenamientos latinoamericanos, lo que no impide la unificación dentro de un marco jurídico común a través de un tejido de comunicación plural. ${ }^{7}$

6 En este sentido, Garro, Alejandro, "Armonización y unificación del derecho privado en América Latina: esfuerzos, tendencias y realidades", Conferenze e Seminari, Roma, Centro di Studi e Ricerche di Diritto Comparato e Straniero, Saggi, vol. 5, 1992, p. 227.

7 Tito Añamuro, John, "Razones para un modelo de integración flexible del derecho contractual latinoamericano", en Pampillo Baliño, Juan Pablo (coord.), Derecho supranacional..., cit., pp. 519 y ss. 
Esta revista forma parte del acervo de la Biblioteca Jurídica Virtual del Instituto de Investigaciones Jurídicas de la UNAM

Justamente con base en esto último, la línea trazada por la ciencia jurídica europea y latinoamericana casa con la idea de reducir la dispersión y construir en consecuencia un bloque común. Sobre ello, una valoración daría cuenta de un saldo positivo a la unificación europea, merced a una estrategia de convergencia auténtica, y uno negativo a la latinoamericana, merced a sus iniciativas embrionarias. Las diferencias llegan a ser en este caso abismales.

América Latina está aún anclada en el tradicional concepto de soberanía de Estado (no hay una cesión efectiva en materia de regulación jurídica) y carece, entre otras cosas, de una fuente institucional de política legislativa y producción de derecho comunitario.

Europa, en cambio, se funda en una unidad económica y política, y en lo jurídico, el objetivo de uniformización, no descansa sólo en la doctrina, sino en el ámbito institucional de la política de la UE.

En suma, América Latina es el imperio de la diversidad jurídica, y Europa lo es de la tendencia a la unidad.

\section{Hacia un programa de compromisos: supuestos de hecho comunes}

Una premisa de partida es que tras la diferencia de sistemas de derecho latinoamericanos descansan supuestos de hecho comunes - piénsese en el daño por responsabilidad objetiva del fabricante - frente a los que sería conveniente establecer soluciones comunes o cuando menos un juicio de valoración común.

No obstante, tales situaciones no justifican por sí solas la aplicación de un método de uniformización. Se precisa vestir esos hechos de un ropaje que sea suficiente para convertirlos en situaciones de derecho. Ello no es fácil, en orden a que haría falta, por un lado, una maquinaria análoga a la unificación europea, y por otro, una voluntad política de integración económica de los Estados latinoamericanos, lo cual es difícil de llevar a cabo o, por lo menos hoy, prematuro. Pero, como dijimos al inicio de este trabajo, es posible coadyuvar a tal destino. Aunque la construcción de la armonización carezca de eficacia directa, en la práctica no deja de ser un aporte anclado en el objetivo. Por ello, una buena razón para motivar tal tendencia es la búsqueda de unas bases que la sustenten.

Para tal efecto, dos acontecimientos son relevantes: primero, el admitir la existencia de situaciones de hecho comunes y, segundo, la influencia 
Esta revista forma parte del acervo de la Biblioteca Jurídica Virtual del Instituto de Investigaciones Jurídicas de la UNAM

y uso de material jurídico de derecho extranjero para regular esas situaciones de hecho. Este último incluye la labor de desarrollo, adaptación, transformación y evolución de la doctrina de América Latina.

Ahora bien, sobre la base de estas dos ideas podría decirse, a priori, que el modo a través del cual la dispersión legislativa se convierte en lesiva es cuando ante un objeto común [rectius: supuesto de hecho común] se regula un enjambre de soluciones distintas, sin tomar en cuenta que éstas tienen origen en la influencia del derecho privado europeo o del derecho norteamericano, según el caso. ${ }^{8}$

Así las cosas, podría afirmarse que si se advierte la existencia de problemas comunes, las soluciones deberían ser también comunes, porque además, el legislador y el juez latinoamericanos utilizan curiosamente el mismo material de información, y si no, por lo menos sus pautas sustanciales. Pero como hay diferencia de política jurídica en los distintos países, hace falta el trazo de una estrategia que una esos hilos de la diferencia.

En sentido práctico, es posible dar el salto a soluciones comunes a partir de la creación y puesta en marcha de un programa de compromisos o marco de interrogantes, análisis y soluciones en materia de derecho privado, que podría concluirse con la fijación de pautas latas, a modo de soft law, en cuestiones de derecho contractual, por ejemplo. Ese programa de compromisos es una contribución material importante para acercar el pensamiento jurídico, especialmente por el particular uso de la vía convencional del mutuo proprio. En nuestra opinión, esta sería la vía gradual para superar la difícil barrera de la disparidad.

Si a ello se une la idea de codificación en un momento determinado, ese material se situaría en la cúspide de la información jurídica que necesitaría el legislador a la hora de la formación de unas secuencias jurídicas regulares, en las cuales tendría un valor importante la labor de la jurisprudencia.

No obstante, cabe la desilusión: las limitaciones de tal prospección. Ese programa que encierra materia común, como se expuso antes, no tendría eficacia directa en la práctica; sería tan sólo referencial y de orientación. Haría falta una estructura institucional conjunta que lleve, por un lado, a buen puerto el proyecto, y por otro, que logre un acuerdo sobre su

8 Piénsese en las class action norteamericanas, que tuvieron impacto en nuestro medio a través de la figura de la acción popular y acción de protección de los consumidores frente a las consecuencias negativas de la ejecución de transacciones con empresarios. 
Esta revista forma parte del acervo de la Biblioteca Jurídica Virtual del Instituto de Investigaciones Jurídicas de la UNAM

carácter vinculante. A este efecto, sería interesante comenzar, por ejemplo, con el reanálisis de la idea de contrato, y en el ámbito de las obligaciones, las ideas de deuda y responsabilidad, lo cual no obsta, naturalmente, a que se ponga sobre la mesa de revisión la vigencia de otras figuras o conceptos jurídicos comunes, dentro de los que se puede considerar, entre otros, el análisis económico del derecho. ${ }^{9}$

Así las cosas, ante la disparidad se ha de tener presente la fijación de un objetivo que propugne la armonización y el instrumento que ha de ser útil para ello. En cuanto a lo primero, como se ha visto, no parece existir mayor problema. Sin embargo, en lo segundo hace falta la implementación de una estrategia logística, más allá de un ánimo de conscientización jurídica: un instrumento equivalente a la directiva europea.

Se sabe que en la región no existe un mecanismo de política conjunta para la adaptación de fórmulas jurídicas a derecho interno, y, por ende, no se cuenta con ese instrumento de armonización clave del proyecto europeo, que es la directiva comunitaria. En consecuencia, el legislador latino, no sometido a una regla o directriz superior, se enfrenta a más de un canon a la hora de dictar la norma, lo cual implica que su decisión podría inclinarse ya por la directiva, ya por el texto traspuesto por alguno de los países miembros de la UE, o, lo que es igual, por algún sistema jurídico europeo, especialmente de derecho alemán, francés, italiano o español, como ha sido de ordinario a través de la historia del derecho latinoamericano. ${ }^{10}$

9 Si el concepto de contrato, en la teoría contractual clásica, es el acuerdo de dos o más voluntades destinadas a crear, regular, modificar o extinguir relaciones jurídicas, en el análisis económico del derecho el contrato es el instrumento que facilita la realización de intercambios entre agentes económicos que valoran los bienes objeto de negociación de manera distinta, y no sólo para transferir riesgos de la actividad económica, sino para incrementar la utilidad de las partes. Con base en el análisis económico del derecho es posible recrear categorías ancladas en la teoría jurídica tradicional. Se tendría, por ejemplo, una visión diferente de la conciliación: esto que no siempre conviene conciliar, sino ir a juicio, dependiendo del grado de información que se tenga de la controversia y del grado de aversión al riesgo de las partes, puede verse en Tito Añamuro, John, "No siempre conviene firmar la paz, sino el conflicto: frente a los modelos alternativos de solución de controversias", Revista de Derecho, julio de 2012, pp. 132 y ss.

$10 \mathrm{Al}$ respecto, Catalano, Pietro, "Diritto romano e paesi latino-americani", Labeo 20, 1974, pp. 433 y ss.; Schipani, Sandro, "El Código Civil español como puente entre el sistema latino americano y los códigos europeos: apuntes para una investigación sobre la referencia a los principios generales del derecho", Revista de Derecho Privado, junio de 1997, pp. 427 y ss.; Castán Vázquez, José María, La influencia de la literatura jurídica española en las 
Esta revista forma parte del acervo de la Biblioteca Jurídica Virtual del Instituto de Investigaciones Jurídicas de la UNAM

Por lo tanto, de no lograr un proyecto de armonización ni un instrumento que lo ejecute, la asimetría aumentaría por las múltiples interpretaciones que se hacen de la normativa extranjera y por las constantes transformaciones socioeconómicas. Nos mantendríamos en una plataforma que carece de apoyo de la literatura jurídica, de crítica de la doctrina, de la contribución de la jurisprudencia, incluso de la participación de empresas, de profesionales y de organizaciones sociales.

Esta asimetría es un fenómeno distinto del método de codificación iberoamericana. Sin embargo, sus elementos sustanciales podrían retomarse en orden a que en aquella época una cosa era aspirar a fijar el derecho, sugerir iniciativas conducentes, e incluso proponer planes bien meditados para encauzar ese proceso, y otra diferente, llevar a cabo y a buen éxito ese cúmulo de proposiciones; esto es, confeccionar nuevas normas capaces de sustituir con eficacia a la institucionalidad jurídica en vigor. ${ }^{11}$

Por último, y estando a lo expuesto, no parece difícil admitir que el análisis de nuestro entorno descubre un catálogo de problemas, intereses y supuestos de hecho que precisan respuestas con objetivos comunes, y si a ello se agrega el ánimo por regularlas, se podría concluir que lo que hace falta es quizá sólo unir los huidizos hilos de esa diversidad.

\section{BASES PARA UN IUS COMMUNE PRIVADO}

LATINOAMERICANO: BREVE ANÁLISIS

\section{Ius commune indiano}

La autoridad de un modelo de razonamiento común por encima de la diversidad que presentan los iura propria es un fenómeno que rige casi exclusivamente el entorno europeo del ius commune de finales del siglo XI, que nace en Bolonia y concluye, previo a las corrientes de codificación, en la pandectística alemana del XIX. ${ }^{12}$

codificaciones americanas: discurso leído el 23 de enero de 1948, Madrid, Real Academia de Jurisprudencia y Legislación, 1984, pp. 153 y ss., y Galgano, Francesco, Atlas de derecho privado comparado, Barcelona, 2001, p. 126.

11 Así, Guzmán Brito, Alejandro, Historia de la codificación civil en Iberoamérica, Navarra, Aranzadi, 2006, pp. 78 y ss.

12 Una exquisita descripción histórica del derecho latinoamericano a la luz de la influencia del pensamiento jurídico francés, español y alemán. Rabinovich-Berkman, 
Esta revista forma parte del acervo de la Biblioteca Jurídica Virtual del Instituto de Investigaciones Jurídicas de la UNAM

Si bien es una posibilidad real defender la existencia de un ius commune indiano, éste no es equivalente al europeo. ${ }^{13}$ La razón descansa en que el derecho común indiano se funda en la vigencia de un cuerpo organizado de reglas y no de principios de aplicación del derecho, según se ve en la Recopilación de las Leyes de los Reynos de las Indias de 1680, muy a pesar incluso, de que la Corona de Castilla reconociera validez y vigencia a derechos consuetudinarios indígenas, en tanto no se opusieran a la fe ni a la legislación reales. ${ }^{14}$

Desde nuestra óptica, la unidad jurídica se identifica en esta etapa con la imposición normativa de un derecho positivo extraño, que llegó a convertirse en derecho general, incluso por encima del derecho castellano y del ius commune europeo, que a este efecto regían sólo a modo supletorio; es decir, en defecto del derecho indiano, y no con la cohesión de un pensamiento jurídico común a todos los pueblos de la nueva Iberoamérica.

Este derecho no fue fruto de la interacción de ideas entre esos pueblos ni suscitó su legitimación desde el ámbito de lo particular. De modo que en esta lógica, tiene razón Mirow cuando afirma que

...el derecho colonial respondía a intereses más de corte político y económico que de desarrollo jurídico, la construcción de un derecho privado indiano justificó más bien la extracción económica y ocupación del patrimonio de las colonias, por lo que su valor jurídico fue en realidad efecto de un estratégico control económico y social de posesiones res nullius, de difícil vigilancia desde la Corona, y de una sociedad que arrostraba convulsionada el cambio de los hechos. ${ }^{15}$

Ricardo, Los principios generales del derecho latinoamericano, Buenos Aires, Astrea, 2006, pp. 208 y ss.

13 Guzmán Brito, Alejandro, Historia de la codificación civil..., cit., p. 31.

14 Ampliamente, Rabinovich-Berkman, Ricardo, Los principios generales del derecho latinoamericano..., cit., pp. 194 y ss.

15 El autor señala que se pone de manifiesto uno de los móviles troncales de la arquitectura del derecho indiano y del derecho privado en especial al argüir que "the very nature of exploration and conquest were defined in terms of private law rather than public rights and responsabilities, explorers wishing to undertake conquest had to enter into a private contract with the crown called a 'capitulación', and these contracts were sometimes even prepared and executed after the fact, v, in extensor", Mirow, Mattew, Latin American Law: a History of Private Law and Institutions in Spanish America, Texas, 2004, pp. 1114 y ss. 
Esta revista forma parte del acervo de la Biblioteca Jurídica Virtual del Instituto de Investigaciones Jurídicas de la UNAM

Por lo que si se quiere extraer de ello alguna conclusión, en nuestra opinión, se podría afirmar que difícilmente puede defenderse un pensamiento jurídico que sea común a las exigencias tanto de los vastos pueblos indígenas como de los de la Península, no sólo por la polaridad de intereses que representaban, sino por la ausencia de un verdadero acercamiento a las necesidades de los sujetos pasivos del derecho indiano, lo cual implica desterrar la idea de existencia de un auténtico ius commune indiano. No obstante, desde el plano positivo, un examen de esas normas comunes podría servir a los objetivos de unidad que se pretende.

Cuánto me gustaría afirmar la existencia de una auténtica unidad jurídica en Latinoamérica, pero temo que ello no es del todo posible. Dudo de la existencia del desarrollo progresivo de un factor de cohesión jurídico entre los pueblos de la vieja Iberoamérica. Lo único que podría admitirse es la presencia de una unidad positiva de contenido jurídico propio del antiguo régimen, que de ningún modo es análogo al objetivo de creación de un pensamiento jurídico aplicable por y sobre la diversidad de la tradición legal de los pueblos que lo integraron, sino, más bien, como opina Mirow, con un claro fin económico y político. Por todo ello, se consideran como objeciones relevantes al ius commune indiano los intereses políticos, económicos y jurídicos, que lo motivaron.

En cuanto al primero, resulta difícil admitir que la arquitectura del derecho indiano no haya sido consecuencia de una previa estrategia política. Al contrario de lo que opina Guzmán Brito, consideramos que el hecho político relevante para la creación ulterior de un sistema jurídico indiano fue la orden de incorporación de las Indias a la Corona de Castilla. Es más, la creación de esas reglas jurídicas no fue más que la herramienta que se requería para justificar la extracción y el control económico de los nuevos bienes que se incorporaron al tráfico jurídico. De modo que resulta más que discutible afirmar el desarrollo autónomo o paralelo del derecho a la política, como sostiene el citado autor, cuando en realidad existió entre ambos un vínculo de jerarquía que desnaturalizó la idea de comunidad jurídica, no sólo por imposición política "desde arriba" a la creación del derecho, sino por la ausencia de una de las condiciones clave de la unidad: la supranacionalidad, supraterritorialidad o suprapopularidad, como ha llamado Pérez-Prendes a los ca- 
Esta revista forma parte del acervo de la Biblioteca Jurídica Virtual del Instituto de Investigaciones Jurídicas de la UNAM

racteres jurídicos unitarios que presenta el fenómeno de la integración o unidad jurídica. ${ }^{16}$

En este último caso, no hace falta una exhaustiva indagación para saber que no existieron secuencias jurídicas comunes a todos los pueblos, sino, por el contrario, una vinculación jurídica vertical a la Corona. A lo cual, agrega Mirow que difícilmente podría propugnarse un derecho común, si incluso el idioma en que se presentaban los nuevos textos jurídicos era totalmente extraño para sus destinatarios, y su contenido casi una réplica del derecho de Castilla, especialmente en temas principales de derecho privado, como familia, sucesiones, propiedad y contratos, ${ }^{17}$ los cuales se mantienen.

En cuanto a lo segundo, existe una clara anteposición de lo económico a lo jurídico. Así, la creación de un sistema de derecho y de sus instituciones jurídicas sirvió, en realidad, a las necesidades de conquista y colonización de los vastos territorios de la Corona.

Así, existen estudios recientes que han comenzado a abordar la función del derecho como un mecanismo de hegemonía política, económica y cultural en América Latina. ${ }^{18} \mathrm{Al}$ respecto, sirven las dos razones de Mirow para demostrar la objeción a la autonomía de la unidad del derecho indígena: la primera, que el derecho fue esencialmente un instrumento de control económico y social sobre las posesiones distantes de la Corona, y la segunda, que el derecho facilitó la extracción de riqueza desde las colonias.

En orden a la primera, la ley y la administración de justicia no cumplían sólo importantes funciones de gobierno, sino que servían a éste como su mejor instrumento. En orden a la segunda, la obtención de metales preciosos y la asignación de trabajos forzados en minería y agricultura a indios y esclavos fue en realidad el objeto de la extensión de la legislación de Castilla hacia los nuevos destinatarios y sus tierras. Todos los aspectos de la propiedad individual, herencia, posesión y actividades comerciales fueron cuidadosamente controlados por el derecho peninsular y por leyes creadas específicamente para las colonias.

Finalmente, en cuanto a las objeciones de orden jurídico, es posible afirmar que la legislación de derecho indiano no fue la expresión de un

16 Pérez-Prendes, José Manuel, Historia del derecho español, Madrid, Universidad de Complutense, 2004, pp. 143-162.

17 Mirow, Mattew, Latin American Law..., cit., p. 15.

18 Ibidem, p. 11. 
Esta revista forma parte del acervo de la Biblioteca Jurídica Virtual del Instituto de Investigaciones Jurídicas de la UNAM

espíritu jurídico común a sus destinatarios. La idea de comunidad, que atrae tanto como puede la diversidad [rectius: la mantiene en un nivel de estabilidad], es una condición que difícilmente se pone en evidencia en la creación de este derecho. Y por más que en el sistema de fuentes colonial el derecho romano haya tenido un valor de consulta o solución jurídica supletorios, sus ideas e instituciones no se fraguaron en el estudio de derechos locales, costumbres y prácticas de intercambio, al contrario de lo que ocurrió en el proceso del ius commune europeo, especialmente en orden a la labor de los glosadores y los comentaristas. ${ }^{19}$

En sí, como apunta Rabinovich, "la supervivencia de los ordenamientos jurídicos indígenas no fue grande".$^{20}$ Descansa la razón de ello en el control político de la norma desde la Corona; esto es, que en la Recopilación de Indias, el monarca se reservaba la derogación o modificación a placer de la normativa indígena; prueba de ello es el siguiente texto de la real cédula: "Por la presente las aprobamos y confirmamos (el derecho indígena) en tanto Nos podamos añadir lo que fuéremos servido y nos pareciere que conviene a nuestro servicio". ${ }^{21}$

De este modo, la unidad jurídica que nos interesa no descansa en la mera aproximación normativa, sino en una razón material profunda y creadora de un espíritu y conciencia de unidad jurídica común, similar a la del ius commune europeo. Coing tiene razón, en este sentido, cuando alega que la selección jurídica del ius commune no valora precisamente las normas y reglas del derecho romano, sino más bien sus conceptos e instituciones, en orden a que éstos alcanzan un grado mayor de estabilidad a la postre. ${ }^{22}$

Ello quiere decir que la idea de unidad privilegia la ratio scripta de los institutos jurídicos a la norma stricto sensu. Como el sistema de derecho indiano carece de esas pautas generales de ratio scripta, que se anteponen al plano positivo, difícilmente se puede sostener la idea de unidad común. Al lado de ello, el concepto de cultura o identidad jurídica indiana resulta un tema imposible de aceptar.

Así las cosas, en la actualidad, y para superar tal vacío, hace falta coordinar conceptos estables, comunes y aplicables a los distintos siste-

19 En este sentido, Coing, Helmut, "Roman Law as ius commune on the Continent", Law Quarterly Review, 1973, pp. 514-516.

20 En este sentido, Rabinovich-Berkman, Ricardo, Los principios generales del derecho latinoamericano..., cit., pp. 198 y ss.

21 Idem.

22 Coing, Helmut, op. cit., pp. 514-516.

D. R. C 2016. UNAM, Instituto de Investigaciones Jurídicas, Boletin Mexicano de Derecho Comparado, núm. 146, pp. 253-279. 
Esta revista forma parte del acervo de la Biblioteca Jurídica Virtual del Instituto de Investigaciones Jurídicas de la UNAM

mas jurídicos latinoamericanos o, como afirma Zimmermann, una unidad intelectual ${ }^{23}$ en virtud de la cual, como ya se dijo en líneas anteriores, se ajusten las soluciones a la práctica de un modo tal que se privilegien las condiciones de estabilidad a las de universalidad. Y como en tal prognosis es poco concluyente el recurso histórico al ius commune indiano, corresponde al proyecto de armonización rastrear, procesar y organizar el derecho privado actual de nuestros pueblos y comunidades indígenas, que fue puesto en la sombra por la Corona en su momento y por el derecho positivo formal en época de la Ilustración.

\section{Derecho romano}

Un buen punto de partida histórico-crítico de la ejecución de un eventual proceso de armonización en materia contractual sería el valor del sistema romano en la construcción del derecho positivo latinoamericano, especialmente por su influencia en el ámbito de la diversidad de codificaciones.$^{24}$ En efecto, tras la independencia, y análogo al fenómeno de recepción del derecho romano en Europa ${ }^{25}$ los nuevos Estados admitieron como fundamento de sus legislaciones el papel preponderante del derecho romano, ante todo por su influyente valor científico. ${ }^{26}$ Prueba de ello fue que la tarea de codificación se elaboró no sólo sobre una fuerte base de institutos romanos, sino "sin imposición directa o indirecta de ninguna autoridad política". ${ }^{27}$ Así, la autonomía institucional del sistema

23 Zimmermann, Reinhard, "Das römisch kanonische ius commune als Grundlage europäis cher Rechtseinheit", Juristenzeitung, 1992, p. 1.

$24 \mathrm{Al}$ respecto, Schipani ("A propósito di diritto romano, rivoluzioni, codificazioni”, Index, 14, 1986, pp. 8 y ss.) apunta que muy a pesar de que el Código de Napoleón llegó a ser, en su momento, el modelo formal por excelencia de la codificación americana, el fenómeno codificador asumió como base fundamental el derecho romano con el típico papel unificante y constructivo de un sistema que integró la costumbre, el derecho natural y el Racionalismo, a tal punto que en numerosas ocasiones la solución adoptada por los códigos americanos se acercaba más al derecho romano que al Código civil napoleónico.

25 Fernández Buján, Antonio, "Derecho romano y sistema jurídico iberoamericano", en Iglesias Prada, Juan Luis, Estudios jurídicos en homenaje al profesor Aurelio Menéndez, Civitas, 1996, vol. 4, p. 4181.

26 Idem.

27 Díaz Bialet, Agustín, "La transfusion du droit romain", Revue Internationale des Droits de l'Antiquité, 13, 1971, pp. 471-477.

D. R. (C) 2016. UNAM, Instituto de Investigaciones Jurídicas, Boletín Mexicano de Derecho Comparado, núm. 146, pp. 253-279. 
Esta revista forma parte del acervo de la Biblioteca Jurídica Virtual del Instituto de Investigaciones Jurídicas de la UNAM

jurídico romano exhibía en América Latina una adelantada impronta científica. ${ }^{28}$

Quizá por ello en la actualidad Zimmermann opine que el derecho romano puede servir como una auténtica teoría general del derecho privado europeo. ${ }^{29}$ En nuestra opinión, podría agregarse que la extracción de esos principios comunes debería nutrirse de un efectivo análisis de derecho comparado; esto es, tanto desde la comparación de categorías jurídicas como desde el prisma del cotejo y crítica de fallos jurisprudenciales que los distintos órganos judiciales emiten en la solución de auténticos supuestos de hecho. De este modo, en la creación de una conciencia jurídica común, tanto la doctrina como la jurisprudencia operarían dentro del marco de exigencia científica y, por ende, fuera de la simple revisión histórica, como es, en este caso el derecho romano.

Con todo, la experiencia jurídica romana llegó a ser un elemento importante de la materia jurídica recogida por las codificaciones latinoamericanas, incluso, como apunta Guzmán Brito, de la cultura jurídica indiana, dado que difícilmente podía prescindirse de ella a la hora de las reformas legislativas. ${ }^{30}$ Por ello, no debe extrañar que en aquella época su negación haya sido sólo excepcional. ${ }^{31}$

\section{A. No todo es Roma}

En el plano de la unidad jurídica, esa experiencia histórica de instituciones romanas y el sustrato que subyace de ella en los códigos actuales

28 Catalano, Pietro, "Sistema y ordenamientos. El ejemplo de América Latina", Roma e America, Diritto Romano Comune, 18, 2004, p. 19.

29 Zimmermann, Reinhard, "Codification: History and Present Significance of an Idea”, European Review of Private Law (ERPL), 1995, pp. 100 y 101.

30 Guzmán Brito recuerda que diversos factores aseguraron un intenso romanismo en los códigos de cada país de Iberoamérica, sobre la base general y tradicional de que el derecho romano, por múltiples vías, había venido a convertirse en un elemento integrante de la cultura jurídica indiana, del que difícilmente podía prescindirse a la hora de tener que emprender la tarea de reformar la legislación; de hecho fueron muy excepcionales las voces que se alzaron en contra del derecho romano. Una, el chileno José Miguel Infante por motivaciones políticas, y otra, el peruano Lorenzo de Vidaurre, quien en su proyecto de codificación civil se apartaba del derecho romano en puntos importantes. Sobre el particular, Historia de la codificación civil..., cit., pp. 127 y ss.

31 A este respecto, Guzmán Brito, Alejandro, Historia de la codificación civil..., cit., pp. 127 y ss.

D. R. C 2016. UNAM, Instituto de Investigaciones Jurídicas, Boletín Mexicano de Derecho Comparado, núm. 146, pp. 253-279. 
Esta revista forma parte del acervo de la Biblioteca Jurídica Virtual del Instituto de Investigaciones Jurídicas de la UNAM

de derecho latinoamericano es relevante sólo si está conectada con la casuística vigente y sin fundarse en el valor per se del derecho romano. ${ }^{32} \mathrm{De}$ este modo, se evitaría el riesgo de dar un salto histórico al pasado desconectado del contexto sociocultural actual y, sobre todo, de las ventajas de la larga e influyente trayectoria del derecho positivo desde la época de las

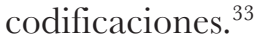

Si bien América Latina y el derecho romano mantienen un vínculo histórico profundo, como apunta Díaz Bialet, como una suerte de transfusión directa del Corpus Iuris o indirecta de la glosa o comentaristas de textos romanos a los primeros códigos latinoamericanos,${ }^{34}$ esto no implica soslayar los privilegios de la normativización (todo un objetivo en el common law, que no sale del trance por descubrir el contrato como categoría jurídica), la subsunción por la norma de nuevos supuestos de hecho fruto de las nuevas tecnologías ni las soluciones judiciales, que se adoptan en cada ordenamiento jurídico.

Se acude al derecho romano - y con razón - como factor de unidad cultural latinoamericano, ${ }^{35} \mathrm{y}$, además, como puente entre el derecho hispano formal de los códigos y los derechos autóctonos americanos. ${ }^{36}$ Sin embargo, esto debe verse a la luz de las exigencias funcionales de la formación de un derecho unificado en América Latina, en orden a que no es posible volver los ojos a Roma sólo para quedar petrificados ante la magnitud inagotable de sus instituciones jurídicas, sino para servirse de ellas en lo que les queda de útiles. Así, por ejemplo, no será posible unificar los derechos reales sobre la base del viejo ius rerum de las Institutas, por la poderosa razón de que ello lapidaría los avances de la era industrial y, hoy en

32 Así las cosas, no es el derecho romano la única fuente de la que puedan emanar propuestas de solución a problemas actuales, sino más bien el aporte de todas las áreas del conocimiento, sin exclusividad de una de ellas.

33 Sobre la negación y las ventajas de la influencia de la Ilustración y del positivismo jurídico, véase Basedow, Jurgen, "Un droit commun des contrats pour le marché commun", RIDC, 1998, p. 9.

34 Véase en este sentido, Díaz Bialet, Agustín, "La transfusion du droit romain", op. cit., p. 471 .

35 Así, Fernández Buján, Antonio, "Derecho romano y sistema jurídico iberoamericano”, en Iglesias Prada, Juan Luis, op. cit., p. 4189.

36 Ello a propósito de las reuniones científicas y de los plenos de los congresos iberoamericanos llevados a cabo desde los años setenta. Con más detalle, véase Fernández Buján, Antonio, "Derecho romano y sistema jurídico iberoamericano", en Iglesias Prada, Juan Luis, op. cit., p. 4189. 
Esta revista forma parte del acervo de la Biblioteca Jurídica Virtual del Instituto de Investigaciones Jurídicas de la UNAM

día, de la era tecnológica al ser aquél un modelo hipotecario anclado en una sociedad prefeudal, agraria y de vieja administración romana.

Una cosa distinta es recuperar, como acierta Castresana, la idea matriz del ius gentium a los estándares actuales de integración jurídica, ${ }^{37}$ en orden a que su operatividad ha quedado demostrada con la experiencia del proyecto integrador europeo. ${ }^{38}$ Por lo tanto, tampoco debe resultar extraña la recepción del ius gentium en América Latina ${ }^{39}$ en época de las labores de codificación, ${ }^{40}$ ni que se vuelva a ella para proyectar la posible unidad del derecho privado latinoamericano, claro está, no sin contrastarla antes con la realidad empírica que recogen las legislaciones.

Así las cosas, lo relevante de los materiales romanos reside no tanto en la esperanza de que viejos institutos den aún soluciones reales, sino que bajo el prisma del análisis científico se vea en ellos un elemento más del objeto de indagación. ${ }^{41}$

37 Como propugna Castresana ("Apuntes sobre un modelo histórico de integración jurídica”, Iura, Rivista Internazionale di Diritto Romano e Antico, 55, 2004, pp. 40-46”), en relación con el ius gentium, para el proceso europeo de armonización interesa conocer, por un lado, qué conceptos sirven para elaborar una construcción jurídica transnacional y, por otro, qué tipo de intervenciones operan tales conceptos sobre la producción jurídica existente. Concluye la autora señalando que "el ejemplo de renovación jurídica que materializa el ius gentium y que explica históricamente el Derecho romano es, sin duda, un modelo de integración jurídica que puede ser útil hoy, al menos en algunos aspectos importantes del proyecto de constitución de un Derecho civil común europeo". En palabras de la autora, se trataría del reconocimiento de un "macro modelo histórico de integración".

38 Así, Castresana, Amelia, op. cit., p. 33.

39 Fernández Buján, Antonio, "Derecho romano y sistema jurídico iberoamericano", en Iglesias Prada, Juan Luis, op. cit., pp. 4186 y 4187.

40 Idem.

41 Eso y no más. Ello por cuanto resulta indefendible la validez intemporal de las soluciones romanas en la realidad, y no sólo por su diferencia con el entorno actual, sino porque supone en sí una pieza incómoda, gravosa y clavada en la vía de la evolución científica por hacerla, de ordinario, torpe y circunspecta. Bobbio ("Scienza del diritto e analisi del linguaggio", Riv. Trim. Dir. Proc. Civ., 1950, p. 363), en sentido análogo, sostuvo que "durante siglos se creía que el Derecho romano era no ya un derecho histórico, acaso el más perfecto y más rico de entre los derechos históricos, sino el derecho por excelencia, así como se sostuvo que la lógica aristotélica era la lógica, y la geometría euclidiana era la geometría; pero, su idealización ha acabado por obstaculizar el progreso de la ciencia". No se puede caer, por ello, en el fondo de un romanismo ciego y nostálgico, ni sabio ni culto, que justifique, por ejemplo, como hace De los Mozos (Integración europea: derecho comunitario y derecho común", Revista de Estudios Europeos 3, 1993, pp. 
Esta revista forma parte del acervo de la Biblioteca Jurídica Virtual del Instituto de Investigaciones Jurídicas de la UNAM

\section{B. Reincubar el derecho}

Desde nuestra perspectiva, el impulso de la ciencia jurídica latinoamericana debe reincubarse en un punto de partida nuevo, el cual ha de atraer el aporte de todas las áreas de análisis comprometidas con la integración y evolución del derecho. Con lo cual, escépticos, relativistas, academicistas, historiadores, romanistas, economistas, neoiusnaturalistas, neopositivistas, integracionistas, aislacionistas, entre otros, recrearían la impronta de la investigación científica. Así, nada que esté lejos del aporte debería soslayarse, en razón de que cada uno de ellos contribuiría, como dice Hesselink, con sus propias reglas, sus académicos, sus métodos y sus fuentes para extraer el derecho. ${ }^{42}$

Esta idea descansa en la libertad de movimiento del pensamiento jurídico, que no busca anular la doctrina de opinión contraria, sino la cooperación amistosa, como expone Von Bar, para intentar llegar al mismo horizonte, en cuyo camino es admisible propugnar la idea de existencia de múltiples niveles de aportación jurídica. ${ }^{43}$

En los romanistas recae el compromiso de revisión científica del derecho a modo de aporte, como se viene haciendo en los últimos años. A cuyo efecto el Centro di Studi Giuridici Latinoamericani de la Universidad de Roma Tor Vergata es quizá el referente más importante, pero no el único. Esborraz Fabio, cuyos estudios se gestan en el citado centro de estudios, es el autor que probablemente ha dado el paso más relevante en materia de integración del derecho privado. ${ }^{44}$

3-15), de la traditio del viejo derecho romano como entrega aún en el presente basada solo en la experiencia intelectual de las autoridades romanas, esto es, evitando su entorno más empírico.

42 Hesselink, Martin, "A European Legal Science? On European Private Law and Scientific Method", European Law Journal, Centre for the Study of European Contract Law, paper 2008/02, p. 33.

43 En este sentido, Von Bar, C., Gemeineuropäisches Deliktsrecht, Beck, 1996, pp. 406 y ss. Para este autor, la unificación del derecho contractual europeo debe llevarse por la vía de la interpretación amistosa; esto es, Europe-friendly interpretation.

44 En la tendencia de armonización del derecho contractual latinoamericano, la obra de Esborraz (Contrato y sistema en América Latina, Rubinzal Culzoni SCG, Centro di Studi Giuridici Latinoamericani, 2006) encarna el resultado de investigación quizá con mayor profundidad y atrevimiento para proponer las bases de una arquitectura común desde el derecho de los contratos; ello, además de ser la más actual y completa, al margen de lo cuestionable que podrían llegar a ser sus postulados. 
Esta revista forma parte del acervo de la Biblioteca Jurídica Virtual del Instituto de Investigaciones Jurídicas de la UNAM

Muy a pesar de la crítica, ${ }^{45}$ su redefinición de la idea de contrato nos ha situado en el que debe ser el nuevo punto de partida del camino de unificación: el acuerdo de lo que se entiende por la noción de "contrato", categoría básica, pieza clave o cimiento elemental de la arquitectura del derecho contractual y del derecho privado en general. A partir de allí no parece que sea incoherente reconstruir la idea de un pensamiento contractual común.

En consecuencia, no todo es reducible a Roma. Si bien ayuda a comentar la norma, no lo hace en todos los casos. Lo que sí es incontestable es que el conocimiento de la romanística enriquece la interpretación y la lógica jurídica cuando se aplica la norma, especialmente en los supuestos conflictivos. La argumentación romanística está tan sólo en el marco de soluciones del derecho nachvolzieber (viable), como apuntan frecuentemente los alemanes, lo que la identifica, desde luego, como un elemento más de la estrategia de soluciones, sin perder el rasgo de ser quizá el más relevante.

En efecto, y como no podía ser de otra manera, la propuesta de un código tipo de contratos y obligaciones para América Latina de Schipani, promotor notable de la unidad latinoamericana, es uno de los tributos más trascendentes de la edificación del derecho, que viene siendo el centro de análisis de foros, conferencias y congresos latinoamericanos de derecho romano. ${ }^{46}$ Además, no debe perderse de vista la idea de integración de Unidroit, que plantea la concepción de un único contrato en materia de derecho internacional. ${ }^{47}$

45 Aquella en especial que alude a la subclasificación del "contrato como género próximo o esencia", en la cual el autor insiste en una categoría de contrato cuando se trata de la concurrencia de una sola voluntad, un acto jurídico, distinto de la convergencia de las dos voluntades recíprocas que identifican en sí la idea de contrato. Sobre el particular, ampliamente, Adame Goddard, Jorge (Esborraz, F., Contrato y sistema en América Latina, cit.), Boletín Mexicano de Derecho Comparado, 123, septiempre-diciembre de 2008, pp. 1621-1624, disponible en http://wrere.juridicas.unam.mx/publica/rev/boletin/cont/123/ bib/bib19.htm.

46 Schipani, Sandro, Principios generales del derecho para un "código tipo" de los contratos en América Latina, disponible en http://wrere.edictum.com.ar/miWeb4/Cuba1997.doc.

47 En efecto, el artículo 3.2 de los Principios UNIDROIT sobre los Contratos Comerciales Internacionales, de 2004, establece: "Validez del mero acuerdo. Todo contrato queda perfeccionado, modificado o extinguido por el mero acuerdo de las partes, sin ningún requisito adicional". 
Esta revista forma parte del acervo de la Biblioteca Jurídica Virtual del Instituto de Investigaciones Jurídicas de la UNAM

\section{Códigos civiles, leyes especiales y reglas del derecho de consumo}

El derecho positivo latinoamericano es uno de los materiales de relevancia a efectos de armonización. En tal sentido, deben examinarse dos instrumentos: uno, los principales códigos civiles, que son el chileno, el argentino, el brasileño y el mexicano, y dos, las corrientes de pensamiento que dieron origen a éstos, es decir, la de Andrés Bello en Chile, la de Vélez Sarsfield en Argentina, la de Texeira Freitas en Brasil y la de Justo Sierra en México.

Así, en un primer momento, el derecho positivo recogió en bloque la forma, la estructura y los contenidos del Code francés de 1804 y, en un segundo momento, las innovaciones y sistemática del BGB alemán de 1900, junto con la labor de las escuelas histórica alemana, exégesis francesa, la de la jurisprudencia de conceptos, la de la jurisprudencia de intereses y la escuela libre del derecho, entre otras. Fruto de los cuales salieron a la luz los principales códigos civiles: el chileno de 1855, el argentino de 1869, el brasilero de 1916 y el mexicano de 1860, los que sirvieron de modelo para los demás países de la región, con la particularidad de que marcaron ciertas diferencias de los originales europeos.

Para la armonización, estas particularidades son las que deben ponerse en el centro de la mesa de análisis, a fin de extraer: primero, los supuestos de hecho comunes, y, segundo, las normas jurídicas comunes a los ordenamientos latinoamericanos. Sin dejar de lado la labor de la doctrina y la jurisprudencia y las leyes especiales ex post a los códigos civiles. En orden a esto último, y con vista en la actualidad, deberían considerarse a examen el Código Civil peruano de 1984, por su aplicación normativa a hechos distintos de los moldes seguidos por las corrientes de codificación latinoamericanas, y el Código Civil y Comercial de la Nación de Argentina de 2015 por su revolucionaria reconstrucción del derecho positivo anterior y la unificación en un solo texto de normas civiles y comerciales.

Por último, en línea con este criterio de selección, el derecho de consumo debe formar parte de los materiales de armonización por la poderosa razón de que, desde el prisma de la realidad, es la materia prima con mejor prospección que la del derecho positivo decimonónico, dado que su regulación no está anclada en la larga tradición dogmática de los códigos civiles vigentes, sino tan sólo en un criterio funcional; esto es, en la sencilla fórmula de buscar soluciones prácticas a problemas prácticos, frutos del 
Esta revista forma parte del acervo de la Biblioteca Jurídica Virtual del Instituto de Investigaciones Jurídicas de la UNAM www.juridicas.unam.mx

avance de la ciencia y de la tecnología, de la industria informática y de la globalización de mercados, entre otros modificadores del derecho vigente.

\section{Furistas y grupos de estudio latinoamericanos}

Al lado de los grupos europeos, como la Comisión Lando, ${ }^{48}$ el Study Group on European Civil Code, ${ }^{49}$ el Grupo de Tilburg, ${ }^{50}$ el Common Core of European Private Law, ${ }^{51}$ el Grupo de Pavía, ${ }^{52}$ el Aquis Group ${ }^{53}$ y la reciente Red de Excelencia Common Principles of European Contract Law, ${ }^{54}$ se sitúan los grupos de estudio de derecho privado latinoamericano.

Bajo la premisa de que todos aportan a la creación de derecho, subrayamos la creación, los objetivos y los resultados hasta ahora alcanzados por los grupos de estudio latinoamericanos, que sin criterio de exhaustividad vendrían a ser, entre otros: a) el proyecto de unificación del dere-

48 Uno de los principales grupos de investigación sobre la armonización del derecho contractual europeo es el liderado por Ole Lando, quien tras varios años de trabajo dio a luz la primera obra más importante de la unificación, que son los PECL (Principles of European Contract Law).

49 El Study Group toma el relevo de la Comisión Lando a fin de construir una codificación de derecho privado liderado por Von Bar, aunque el trabajo es más complejo que el primero, sirvió de fundamentos para directrices europeas, una buena muestra de la labor del grupo fueron los Principles of European Law Series.

50 El grupo Tilburg conocido también como European Group on Tort Law tiene un aporte relevante en la actualización y modernización del derecho de daños, sus trabajos pueden verse con amplitud en http://wrere.common-core.org.

51 El Common Core of European Private Law, fundado por Mattei y Bussani, tiene por finalidad la elaboración de un código privado europeo, labor que descansa en un alto nivel de precisión de la unificación de los sistemas jurídicos europeos.

52 El texto del Grupo Pavía, que es un anteproyecto del código europeo de contratos, tiene por característica relevante que engloba las relaciones jurídicas mercantiles, civiles y de consumo, con lo cual puede decirse que sus pretensiones son universales. Un aporte interesante, y no menos polémico, es que suprime del contrato la mención de la causa, que tantos absurdos ha generado en las soluciones judiciales.

53 El Aquis Group tiene por misión la reordenación de la legislación comunitaria, siendo lo más relevante su influencia en la elaboración del Marco Común de Referencia de 2009 .

54 Esta red reúne los trabajos anteriores de manera coordinada y a efecto de elaborar un marco común de referencia para el derecho contractual europeo, la importancia de estos trabajos es que tienen autorización o, si se quiere, legitimidad de la Comisión, así mediante comunicación de febrero de 2003 un plan de acción denominado "Un derecho contractual europeo más coherente". La red está presidida por Schulte Nölke. 
Esta revista forma parte del acervo de la Biblioteca Jurídica Virtual del Instituto de Investigaciones Jurídicas de la UNAM

cho privado en América Latina de la Universidad de La Plata; b) el Centro di Studi Giuridici Latinoamericani de la Universidad Tor Vergata; c) el programa de unificación de la Universidad de Columbia, que dirige el profesor Garro; d) el Centro de Documentación del Grupo para la Armonización del Derecho Privado Latinoamericano de la Universidad Nacional de Rosario; e) el Centro de Investigación e Informática Jurídica de la Escuela Libre de Derecho, con sede en el Distrito Federal de México, que centra una de sus áreas de investigación en la integración latinoamericana desde una óptica de pensamiento relacional; f) algunos trabajos de investigación individuales, como el de Esborraz y su aproximación a la integración jurídica a través del texto Contrato y sistema en América Latina; el de Merryman y Pérez Perdomo con The Civil Law Tradition: An Introduction to the Legal System of Europe and Latin America; ${ }^{55}$ g) La Asociación Americana de Derecho Internacional Privado, fundada en octubre de 2007 en Asunción, que sobre la base de la histórica codificación de derecho internacional privado busca aristas para una integración del derecho moderno; h) el Centro de Estudios de Derecho, Economía y Política, con sede en Asunción, que en materia de integración coopera con la OEA, ALADI, UNIDROIT y las universidades e instituciones Georgetown, Bologna, Heidelberg y Max Planck; i) el proyecto Bases para la Modernización del Derecho Contractual Latinoamericano, de la Universidad del Norte, en Colombia, que se funda también en ese horizonte y, especialmente, la Red Internacional de Juristas para la Integración Americana, que con sede en la Ciudad de México ha iniciado de la mano de Juan Pablo Pampillo Baliño una labor nada asistemática con el fin de hallar lazos comunes en la armonización de los ordenamientos americanos. De hecho, la obra jurídica enciclopédica de cuarenta y tres volúmenes, que engloba derecho público, derecho privado, ciencias fundamentales y auxiliares, supone un cimiento material no sólo relevante, sino histórico.

No son muchos los trabajos orientados a sentar las bases de una conciencia jurídica común a partir de la experiencia europea, y los que existen encuentran en la acusación de copiar y pegar una aproximación tímida y escrupulosa. No por ello dejan de ser un material de apoyo importante para la armonización. Recuérdese que todos los actores aportan

55 Merryman, John y Pérez-Perdomo, Rogelio, The Civil Law Tradition: An Introduction to the Legal System of Europe and Latin America, California, Stanford University Press, 2007. 
Esta revista forma parte del acervo de la Biblioteca Jurídica Virtual del Instituto de Investigaciones Jurídicas de la UNAM

a la convergencia. En tal sentido, los estudios latinos tienen, sin duda, trascendencia, además, porque es factible integrar los errores de unificación europeos en el proceso latinoamericano.

"De los errores se aprende", reza el viejo refrán. Lectura que no tiene otro sentido que gestar crítica. Como apunta Viciano Pastor: "56 "Hay que aprender de la experiencia europea los errores que se han cometido en su integración". Ésa es una de las lecciones que, según el autor, con quien coincidimos, se deben aprender del largo y complicado proceso de integración europea, precisamente porque la experiencia ayuda a comprobar cómo, tras los primeros momentos de mutuas concesiones y afectación a los intereses nacionales, la integración ha llevado a la multiplicación de beneficios para cada país y al desarrollo conjunto de Europa. Pero, como se sabe, esto aún no se ha interiorizado, como sería deseable. Justamente allí nace la importancia de difundir los procesos de integración ajenos, especialmente el europeo, del que "mucho se habla pero poco se conoce en detalle". 57

Sin lugar a dudas, hay muchos más materiales a examinar en el objetivo de crear una cultura jurídica común, que sirva además de base para la actualización constante del derecho positivo latinoamericano. De momento, esta exploración modesta, con riesgo a revisión de todo lo que se ha dicho, descansa en la reflexión e investigación y, especialmente, en el espíritu de gestar un programa conjunto de compromisos, que inicie la ruta a un ius commune privado latinoamericano.

\section{Gonclusiones}

Primera. En el escenario actual, unir los distintos sistemas jurídicos en un tejido de derecho común latinoamericano es aún una acción embrionaria. Las causas descansan no sólo en la diversidad del derecho privado recibido desde las codificaciones, sino en los diversos modelos económicos latinos: unos de libre mercado y otros dirigidos desde el Ejecutivo, que impiden la

56 Viciano Pastor, Roberto, en Silvana Insignares Cera, El proceso de integración europeo, entre lo supranacional y lo intergubernamental, Barranquilla, Ediciones Uninorte, 2011, p. X.

57 Así comenta Viciano Pastor a raíz de la obra de difusión de integración europea que prologa de Insignares Cera (El proceso de integración europeo..., cit., p. XI), la cual, dicho sea de paso, contiene una rica exposición sistemática del engranaje de convergencia europea. 
Esta revista forma parte del acervo de la Biblioteca Jurídica Virtual del Instituto de Investigaciones Jurídicas de la UNAM

formación de un mercado único. Por lo que corresponde, previo a todo y desde nuestra óptica, la gestación desde abajo de una conciencia jurídica común latinoamericana, que dé tránsito, en su momento, a un derecho positivo común.

Segunda. Las iniciativas hacia la armonización jurídica deben organizarse en un programa único de compromisos a fin de evitar aportes aislados y soluciones dispares. Para este efecto, corresponde iniciar, impulsar y materializar una acción comunitaria para la formación de las bases de un ius commune privado. La Red Internacional de Juristas para la Integración Americana con sede en Ciudad de México sería, en este sentido, un buen punto de iniciación y de referencia.

Tercera. En la ruta de la armonización del derecho privado latinoamericano no debe dejarse de lado el aporte de los distintos grupos de investigación, de empresarios, consumidores, sindicatos, grupos y asociaciones de defensa de intereses sociales y ciudadanos en general, en orden a que no sólo aportan los juristas y operadores del derecho a la creación de conocimiento jurídico válido, sino todos los destinatarios de la norma.

\section{BIBLIOGRAFÍA}

ADAME GODDARD, Jorge, "Recensión a Esborraz, F., Contrato y sistema en América Latina", Boletín Mexicano de Derecho Comparado, México, 123, septiembre-diciembre de 2008, disponible en http://wrere.juridicas.unam.mx/ publica/rev/boletin/cont/123/bib/bib19.htm.

BAR von, C., Gemeineuropäisches Deliktsrecht, Beck, 1996.

BASEDOW, Jürgen, "Un droit commun des contrats pour le marché commun", RIDC, 1998.

BobBIO, Norberto, "Scienza del diritto e analisi del linguaggio", Riv. Trim. Dir. Proc. Civ., 1950.

CASTÁN VÁZQUez, José María, La influencia de la literatura jurídica española en las codificaciones americanas: discurso leído el 23 de enero de 1948, Madrid, Real Academia de Jurisprudencia y Legislación, 1984.

Castresana, Amelia, "Apuntes sobre un modelo histórico de integración jurídica", Iura, Rivista Internazionale di Diritto Romano e Antico, 55, 2004.

Catalano, Pietro, "Diritto romano e paesi latino-americani", Labeo 20, 1974. 
Esta revista forma parte del acervo de la Biblioteca Jurídica Virtual del Instituto de Investigaciones Jurídicas de la UNAM

, "Sistema y ordenamientos. El ejemplo de América Latina", Roma e America, Diritto Romano Comune, 18, 2004.

COING, Helmut, "Roman Law as ius commune on the Continent", Law Quarterly Review, 1973.

DíAz BiAlet, Antonio, "La transfusion du droit romain", Revue Internationale des Droits de l'Antiquité, 13, 1971.

Esborraz, Fabio, Contrato y sistema en América Latina, Rubinzal Culzoni SCC, Centro di Studi Giuridici Latinoamericani, 2006.

FERnÁndez BujÁN, Antonio, "Derecho romano y sistema jurídico Iberoamericano", en IGLESIAS PRADA, Juan Luis, Estudios jurídicos en homenaje al profesor Aurelio Menéndez, Madrid, Civitas, 1996, vol. 4.

Galgano, Francesco, Atlas de derecho privado comparado, Barcelona, 2001.

GARRO, Alejandro, "Armonización y unificación del derecho privado en América Latina. Esfuerzos, tendencias y realidades", Conferenze e Seminari, Roma, Centro di Studi e Ricerche di Diritto Comparato e Straniero, Saggi, vol. 5.

GonzÁlez Martín, Nuria, "Unión Europea: bases de su marco jurídico", en Pampillo Baliño, Juan Pablo (coord.), Derecho supranacional, globalización e integración jurídica, México, Porrúa, 2012.

GuZMÁn BRITO, Alejandro, Historia de la codificación civil en Iberoamérica, Navarra, Aranzadi, 2006.

HesselinK, Martin, "A European Legal Science? On European Private Law and Scientific Method", Centre for the Study of European Contract Law, paper 2008/02.

INSIGNARES CERA, Silvana, El proceso de integración europeo, entre lo supranacional y lo intergubernamental, Barranquilla, Ediciones Uninorte, 2011.

Merryman, John y PÉrez-PERdomo, Rogelio, The Civil Law Tradition: An Introduction to the Legal System of Europe and Latin America, California, Stanford University Press, 2007.

Mirow, Mattew, Latin American Law: a History of Private Law and Institutions in Spanish America, Texas, 2004.

Mozos, José Luis de los, "Integración europea. Derecho comunitario y derecho común", Revista de Estudios Europeos 3, 1993.

PAMPIllo BALiÑo, Juan Pablo, "El derecho de la integración americana: una invitación a los juristas a conformar un nuevo ius commune", en PAmPillo BAliño, Juan Pablo (coord.), Derecho supranacional, globalización e integración jurídica, México, Porrúa, 2012. 
Esta revista forma parte del acervo de la Biblioteca Jurídica Virtual del Instituto de Investigaciones Jurídicas de la UNAM

PÉrez-Prendes, Jose Manuel, Historia del derecho español, Madrid, Universidad Complutense.

RABINOVICH-BERKMAN, Ricardo, Los principios generales del derecho latinoamericano, Buenos Aires, Astrea, 2006.

SCHIPANI, Sandro, "A propósito di diritto romano, rivoluzioni, codificazioni”, Index, 14, 1986.

, "El Código Civil español como puente entre el sistema latinoamericano y los códigos europeos: apuntes para una investigación sobre la referencia a los principios generales del derecho", Revista de Derecho Privado, junio, 1997.

, Principios generales del derecho para un "código tipo" de los contratos en America Latina, http://wrwredictum.com.ar/miWeb4/Cuba1997.doc.

Tito AÑamURO, John Alberto, Modernización e integración del derecho contractual latinoamericano, Barranquilla, Ediciones Uninorte, 2012.

-, "Razones para un modelo de integración flexible del derecho contractual latinoamericano", en PAMPILLO BALIÑO, Juan Pablo (coord.), Derecho supranacional, globalización e integración jurídica, México, Porrúa, 2012.

"No siempre conviene firmar la paz, sino el conflicto: frente a los modelos alternativos de solución de controversias", Revista de Derecho, julio, 2012.

, "Hacia un modelo de armonización del derecho contractual latinoamericano", 126, Vniversitas, 2013.

ZIMMERMANN, Reinhard, "Das römischkanonische ius commune als Grundlage europäis cher Rechtseinheit", Juristenzeitung, 1992.

, "Codification: History and Present Significance of an Idea", European Review of Private Law (ERPL), 1995. 